\title{
Prediction of global ionospheric VTEC maps using an adaptive autoregressive model
}

\author{
Cheng Wang ${ }^{1,2^{*}}$, Shaoming Xin ${ }^{3}$, Xiaolu Liu ${ }^{4}$, Chuang Shi ${ }^{1,2}$ and Lei Fan ${ }^{2}$
}

\begin{abstract}
In this contribution, an adaptive autoregressive model is proposed and developed to predict global ionospheric vertical total electron content maps (VTEC). Specifically, the spherical harmonic (SH) coefficients are predicted based on the autoregressive model, and the order of the autoregressive model is determined adaptively using the F-test method. To test our method, final CODE and IGS global ionospheric map (GIM) products, as well as altimeter TEC data during low and mid-to-high solar activity period collected by JASON, are used to evaluate the precision of our forecasting products. Results indicate that the predicted products derived from the model proposed in this paper have good consistency with the final GIMs in low solar activity, where the annual mean of the root-mean-square value is approximately 1.5 TECU. However, the performance of predicted vertical TEC in periods of mid-to-high solar activity has less accuracy than that during low solar activity periods, especially in the equatorial ionization anomaly region and the Southern Hemisphere. Additionally, in comparison with forecasting products, the final IGS GIMs have the best consistency with altimeter TEC data. Future work is needed to investigate the performance of forecasting products using the proposed method in an operational environment, rather than using the SH coefficients from the final CODE products, to understand the real-time applicability of the method.
\end{abstract}

\section{Introduction}

The ionosphere plays an important role in the dynamics of space weather of solar-terrestrial space. The ionosphere is important in matters of national defense, aviation security, economic development, and human life. Ionosphere monitoring using dual-frequency measurements from the Global Navigation Satellite System (GNSS) has been a topic for several decades (Komjathy 1997; De Franceschi and Zolesi 1998; Mannucci et al. 1998; Hernández-Pajares et al. 1999; Schaer 1999). GNSS provides an opportunity for long-term monitoring of the ionosphere with high accuracy and temporal and spatial resolution at relatively low cost, either in a regional context or on a global scale. The Ionosphere Associate Analysis Centers (IAACs) of the International GNSS Service (IGS) (Dow et al. 2009) have been providing reliable global ionospheric maps (GIMs) since 1998

\footnotetext{
*Correspondence: ac@geodesy.cn

${ }^{1}$ Collaborative Innovation Center for Geospatial Information Technology, No. 129 Luoyu Road, Wuhan 430079, China

Full list of author information is available at the end of the article
}

(Hernández-Pajares et al. 2009). The IGS final vertical total electron content (TEC) maps are used for the scientific analysis of the ionosphere and practical applications. However, the IGS final GIM product is released with a time delay of approximately 2 weeks, limiting their application in real-time scenarios, including real-time precise positioning (Shi et al. 2012; Rovira-Garcia et al. 2015) and space missions, such as the Soil Moisture and Ocean Salinity (SMOS) from the European Space Agency (ESA) (Silvestrin et al. 2001; García-Rigo et al. 2011). Rapid GIM products, e.g., UQRG (ftp://newg1.upc.es/upc ionex) and WHUD (ftp://pub.ionosphere.cn) provided by the Technical University of Catalonia (UPC) and Wuhan University (WHU), respectively, are available with oneday latency. Meanwhile, real-time GIMs produced by IAACs will be available in the near future. However, the accuracy of real-time ionospheric products on a global scale might be limited by data availability, as the public real-time data stream is currently more concentrated in certain regions, i.e., North America, Europe, and Australia. In addition, the applications might be limited by a latency of a few seconds needed to get the real-time 
products of ionosphere. Thus, short-term predictions of global ionospheric vertical TEC (VTEC) maps are important for technological applications. Since real-time satellite orbits and clocks are available, the limiting factor in high-accuracy positioning is the ionospheric delay (Rovira-Garcia et al. 2015). Short-term predictions could be used to generate real-time global VTEC maps (Orús Pérez et al. 2010). Along with many other applications, such as automobiles, road mapping, and location-based services, short-term predictions could be used to achieve sub-meter accuracy for mass-market single-frequency receivers (García-Rigo et al. 2011).

To meet the needs presented by the study of ionospheric physics and application in GNSS positioning, a few ionospheric models have been constructed, i.e., the Klobuchar model (Klobuchar 1987), the International Reference Ionosphere (IRI) model (Rawer et al. 1978; Bilitza and Reinisch 2008; Bilitza et al. 2011), and the NeQuick model (Radicella and Leitinger 2001; Nava et al. 2008). Many scholars have investigated the accuracy of these models for different regions of the world during periods of different solar and geomagnetic activities (Abdu et al. 1996; Araujo-Pradere et al. 2003; Bertoni et al. 2006; Lee and Reinisch 2006; Bhuyan and Borah 2007; Mosert et al. 2007; Adewale et al. 2011; Nigussie et al. 2013; Okoh et al. 2013; Olwendo et al. 2013; Wichaipanich et al. 2013; Wang 2016). The annual mean of the root-mean-square (RMS) of the differences between IGS GIMs and IRI predictions in 2014 was approximately 10 total electron content units (TECU, $10^{16} \mathrm{el} / \mathrm{m}^{2}$ ) (Wang et al. 2016). Thus, these empirical models are suitable for use in the scientific study of ionosphere behavior, which can provide predictions of the ionosphere, but they might not be appropriate for other applications that require high accuracy. Additionally, other models are built to represent the majority of the variations and the temporal-spatial distribution of the global or regional ionospheric TEC. For instance, global models are constructed by using empirical orthogonal function analysis to reproduce the major variations in TEC and the ionospheric climatology (Ercha et al. 2012; Wan et al. 2012; Mukhtarov et al. 2013). Also, regional models are studied over many countries and regions by using different methods to capture more details of the ionosphere (Bouya et al. 2010; Habarulema 2010; Chen et al. 2015; Fuller-Rowell et al. 2016; Huang et al. 2017).

It is possible to obtain better VTEC maps by forecasting in the short term than those derived from empirical models. Several methods have been developed for ionospheric forecasting in recent years, such as the autocorrelation method (Muhtarov and Kutiev 1999), the autoregressive moving average (ARMA) method (Krankowski et al.
2005), a method based on neural networks (Tulunay et al. 2006), and an autoregressive model for predicting VTEC values (Karthik et al. 2012). However, many predictions are investigated at a certain location or over a regional area. In terms of global ionospheric VTEC maps forecasting, the Center for Orbit Determination in Europe (CODE), an IAAC, has provided predicted ionospheric products (one- and two-day-ahead VTEC maps, named C1PG and C2PG, respectively) for public access since 2008, via the FTP server of the Crustal Dynamics Data Information System (CDDIS, ftp://cddis.gsfc.nasa.gov/). Shortly afterward, the European Space Agency (ESA) and the Technical University of Catalonia (UPC) released their two-day-ahead VTEC maps through the FTP server of CDDIS, as well. Least-squares collocation (LSC) is used by CODE to extrapolate the coefficients of spherical harmonics $(\mathrm{SH})$ for predicting VTEC maps (Schaer 1999). UPC VTEC forecasting is based on the discrete cosine transform (DCT) technique (García-Rigo et al. 2011). Moreover, a linear regression module is used to forecast the DCT coefficients and predict VTEC maps. Unlike the two methods above, the development of adaptive autoregressive modeling (AARM) for the prediction of global ionospheric VTEC maps will be presented in this manuscript. The first section of the manuscript is devoted to a detailed explanation of the AARM for ionospheric forecasting. The performance of AARM forecasting is investigated through a comparison between VTEC map predictions and IGS final products. Additionally, a comparison between VTEC predictions and external independent JASON data is conducted. Finally, conclusions are summarized in the last section.

\section{Basic methodology of ionospheric forecasting Technical description of AARM}

Autoregressive (AR) models have been widely used in several subject areas, such as economics (Cheng 1982), geophysics (Weiss et al. 2012), and climate change (Gu and Jiang 2005; Lee et al. 2016). First, the basic methodology of the autoregressive model (Hamilton 1994) is presented as follows:

$$
x_{t}=a_{1} x_{t-1}+a_{2} x_{t-2}+\cdots+a_{p} x_{t-p}+\varepsilon_{t}
$$

where $\left[x_{t}\right]$ is the time series; $\left[a_{1}, a_{2}, \ldots, a_{p}\right]$ is the vector of unknown AR coefficients, which can be estimated by least square estimation (LSE); $p$ is the order of the AR model; and $\left[\varepsilon_{t}\right]$ is the zero-mean white noise.

The usual strategy for one-step forecasting is performed using the estimated AR coefficients, as depicted in the following equation:

$$
x_{n+1}=a_{1} x_{n}+a_{2} x_{n-2}+\cdots+a_{p} x_{n-p}+\varepsilon_{n+1}
$$


where $x_{n+1}$ is the forecasting parameter; $n$ is the total number of the observed time series; and $\varepsilon_{n+1}$ is the corresponding noise.

The selected order determines the goodness of fit of the model, as well as the accuracy of the forecast. Some researchers have adopted multiple a priori computations of the model order, up to a predefined maximum order $\mathrm{M}$, to select the order that gives the minimum fitting error (Costa and Hengstler 2011). The predefined maximum order $\mathrm{M}$ is usually determined experimentally. However, the order M may not be high enough to construct a model and forecast with high accuracy. On the other hand, if the order $\mathrm{M}$ is selected to be too high, a larger number of computations will be required. To avoid excessive computational cost, an adaptive approach for model order selection is presented. The modeling computation starts with a predefined minimum order N. Subsequently, modeling of the order $\mathrm{N}+1$ is also carried out. An $F$ test is used to demonstrate whether there is a significant difference between the two models with different orders. The formula of F-statistics is as follows in Eq. (3):

$$
F=\frac{\left(\mathrm{RSS}_{N}-\mathrm{RSS}_{N+1}\right) /\left(f_{N}-f_{N+1}\right)}{\mathrm{RSS}_{N+1} / f_{N+1}}
$$

where RSS is the residual sum of squares; $\mathrm{N}$ is the predefined minimum order; and $f$ is the degrees of freedom.

In hypothesis testing, if the F-statistic is smaller than the critical value $F_{\alpha}$, there is no significant difference between the two models. In this case, the lower-order $\mathrm{N}$ will be selected for modeling. Otherwise, one more modeling computation with increased order should be performed until the F-statistics is smaller than the critical value. The flowchart of AARM for extrapolation of $\mathrm{SH}$ coefficients is presented in Fig. 1.

\section{Forecasting global VTEC maps using AARM}

As a reference, the spherical harmonic coefficients produced by CODE, which are available at CODE's FTP, are used to forecast global VTEC maps. To investigate the performance of forecasts during periods of different levels of solar activity, the SH coefficients from final ionospheric products are collected for forecasting VTEC maps in 2009 and 2015. CODE uses data from approximately 200 GNSS stations in the IGS network and other institutions. The VTEC is modeled in a solar-geomagnetic reference frame using a spherical harmonics expansion of up to degree and order 15. Piecewise linear functions are used for representation in the time domain. The time spacing of their vertices is $2 \mathrm{~h}$, conforming with the epochs of the VTEC maps. (Schaer 1999). CODE divides all observations from a given day into 12 sessions, and each session contains $2 \mathrm{~h}$ of data. Therefore, there is

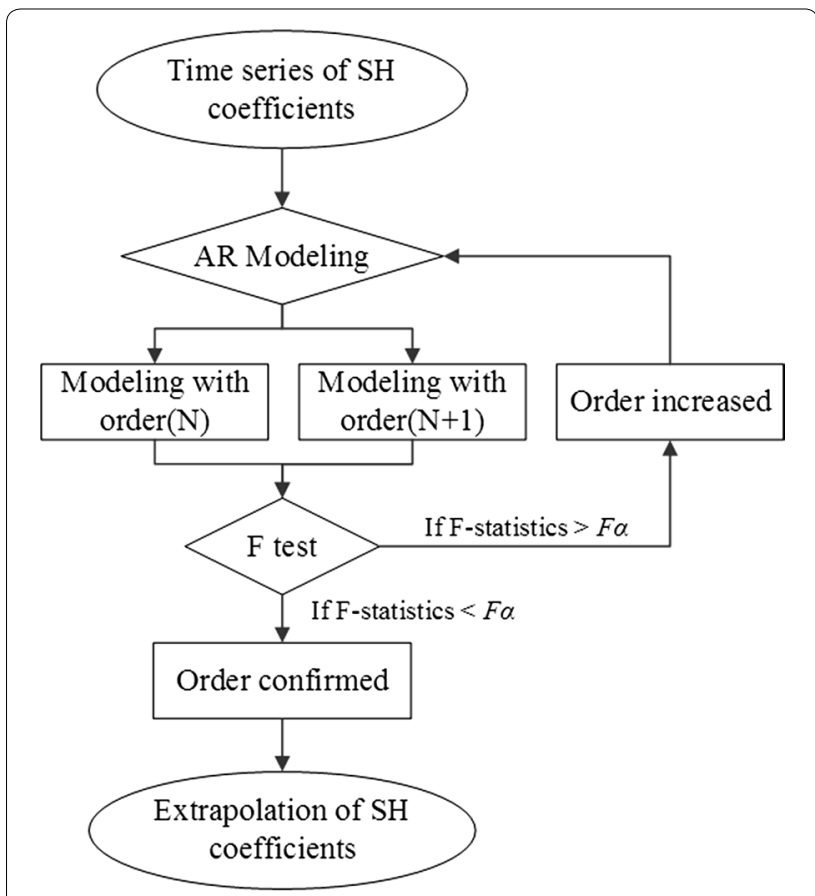

Fig. 1 Flowchart of AARM for extrapolation of SH coefficients

one group of $\mathrm{SH}$ coefficients on the hour of each session starting from 0 UTC to 22 UTC, with 2-hour intervals, and there is one group on the hour 0 UTC the next day (13 groups of coefficients), to be estimated in one-day ionospheric modeling. The number of sessions is changed to 24 in 2015, and each session contains $1 \mathrm{~h}$ of data. Thus, there are 25 groups of SH coefficients starting from 2015. Both the last group of $\mathrm{SH}$ coefficients from the current day and the first group of $\mathrm{SH}$ coefficients from the next day are from the same hour, 0 UTC. The unique SH coefficients at 0 UTC can be the average of those two groups of SH coefficients. Then, a dataset of time series of $\mathrm{SH}$ coefficients could be constructed for forecasting. Since the model order is adaptively determined through AARM, it is possible that the quantity of groups of coefficients in time series will not influence the results of forecasting. In this study, $\mathrm{SH}$ coefficients of 30 days are used to construct a dataset that has $361(30 \times 12+1)$ groups of coefficients in 2009 and $721(30 \times 24+1)$ groups of coefficients in 2015, respectively. There are 12 groups and 24 groups of coefficients to be predicted for the one-dayahead forecasts in 2009 and 2015, respectively. Additionally, a predefined minimum order $\mathrm{N}$ of AR modeling is set to 60 , which corresponds to 5 days of time series of the $\mathrm{SH}$ coefficients in 2009 and 2.5 days of time series of the SH coefficients in 2015. Fisher (1925) suggested a probability of 0.05 as a convenient cutoff level to reject the null hypothesis, though he did not intend this cutoff 
value to be fixed. Many authors have discussed hypothesis testing and the selection of the significance level (Labovitz 1968; Rice 1989; Blackwell 2008; Faul et al. 2009; Harrell 2015). Additionally, a significance level of 0.05 has been used in many research fields, such as neuroscience, genetic studies, and face recognition (Risch and Merikangas 1996; Storey and Tibshirani 2003; Yang et al. 2004; Nieuwenhuis et al. 2011). A significance level of 0.05 is also selected to calculate the critical value of the F distribution in this study. Once the F-statistic becomes smaller than the critical value, the order of the AR model is determined, and consequently, the coefficients would be predicted. It should be noted that $256 \mathrm{SH}$ coefficients would be predicted independently using their own time series to determine their respective adaptive orders for AR modeling. Finally, global ionospheric VTEC maps for one-day-ahead forecasting could be generated using the predicted SH coefficients by Eq. (4), where $\varphi$ is the geomagnetic latitude of the ionospheric pierce point (IPP); $\lambda$ is the sun-fixed longitude of IPP; $n$ and $m$ are the degree and order of the model, respectively; $\tilde{P}_{n m}$ is the normalized associated Legendre function of degree $n$ and order $m$; and $a_{n m}$ and $b_{n m}$ are the predicted SH coefficients.

$$
\begin{aligned}
\operatorname{VTEC}(\varphi, \lambda)= & \sum_{n=0}^{n_{\max }} \sum_{m=0}^{n} \tilde{P}_{n m}(\sin \varphi)\left(a_{n m} \cos (m \lambda)\right. \\
& \left.+b_{n m} \sin (m \lambda)\right)
\end{aligned}
$$

\section{Results and analysis}

\section{Test and reference data}

Solar and geomagnetic activities have a strong impact on the ionosphere. Most common indices, including the sunspot number (SSN), solar radio flux at $10.7 \mathrm{~cm}$ (thereafter referred as to F10.7), and the disturbance storm time index (Dst) are shown in Fig. 2. At solar minimum, all SSN values are less than 50; the F10.7 average is approximately $70 \mathrm{SFU}$, with only a few values above $80 \mathrm{SFU}$; most Dst indices are near zero, except on day of year 203 and several of the following days. In 2015, both the SSN and F10.7 are much larger than those in 2009; all indices have significant fluctuations. Three Dst indices are approximately - $100 \mathrm{nT}$ on day of year (DOY) 77, 174 , and 355.

The CODE final VTEC maps (named CODG) are used as reference data to investigate the performance of the forecasting VTEC maps using the AARM approach (named ARPG), which is described in "Basic methodology of ionospheric forecasting" section. The assessment of forecast performance is performed in terms of the daily average (bias) and root-mean-square (RMS) of the differences between the forecast products and CODE final GIMs, as shown in Eqs. (5) and (6), where $n$ is the total number of grid points of a daily GIM product and
$\mathrm{VTEC}_{p}$ and $\mathrm{VTEC}_{f}$ are the predicted VTEC values in ARPG and final VTEC values in CODG, respectively:

$$
\begin{aligned}
& \text { bias }=\frac{1}{n} \sum_{i=1}^{n}\left(\operatorname{VTEC}_{p}^{i}-\mathrm{VTEC}_{f}^{i}\right) \\
& \mathrm{RMS}=\sqrt{\frac{\sum_{i=1}^{n}\left(\mathrm{VTEC}_{p}^{i}-\mathrm{VTEC}_{f}^{i}\right)^{2}}{n}} .
\end{aligned}
$$

Additionally, an independent source of VTEC measurements observed by a dual-frequency altimeter instrument on the JASON 2 satellite is used to validate the VTEC values of GNSS-derived VTEC maps over oceans, where a few GNSS receivers exist. JASON data have previously been used to validate final IGS ionospheric products (Hernández-Pajares et al. 2009). However, there are two aspects that should be taken into account. First, the GNSS-derived VTEC includes the plasmaspheric electron content contribution, which is typically $10 \%$ during the daytime and as high as $60 \%$ at night (Yizengaw et al. 2008), in contrast to JASON VTEC, covering heights from the bottom of ionosphere to the JASON orbit at an altitude of approximately $1300 \mathrm{~km}$. Unless otherwise indicated, JASON VTEC is hereafter referred to as J2TEC. The amount of GNSS experimental data available over the oceans and in southern latitudes is much less than that in northern latitudes. GNSS-derived VTEC maps over these areas might have lower accuracy. To a certain extent, the comparison of VTEC between J2TEC and GNSS-derived VTEC might allow an estimation of the relative accuracy of the predicted and final ionospheric VTEC maps over the oceans and southern latitudes.

\section{Forecast performance \\ Comparison of predicted VTEC maps}

Global ionospheric VTEC maps are predicted using an adaptive autoregressive model, as described in "Basic methodology of ionospheric forecasting" section. The validation is carried out by comparing the predicted VTEC maps (ARPG) with the CODE final VTEC maps (CODG), in terms of the daily bias and RMS of the differences. The total number of VTEC values for daily GIM products in 2009 and 2015 is equal to 67379 $(71 \times 73 \times 13)$ and $129575(71 \times 73 \times 25)$, respectively. CODE one-day-ahead forecast products C1PG are collected and compared with CODG to provide a reference of validation for ARPG. Figures 3 and 4 show the differences in VTEC maps between forecasting products and the final CODE GIMs in 2009 and 2015, respectively. The annual means of the daily bias values are approximately zero TECU both in 2009 and in 2015. This result indicates 

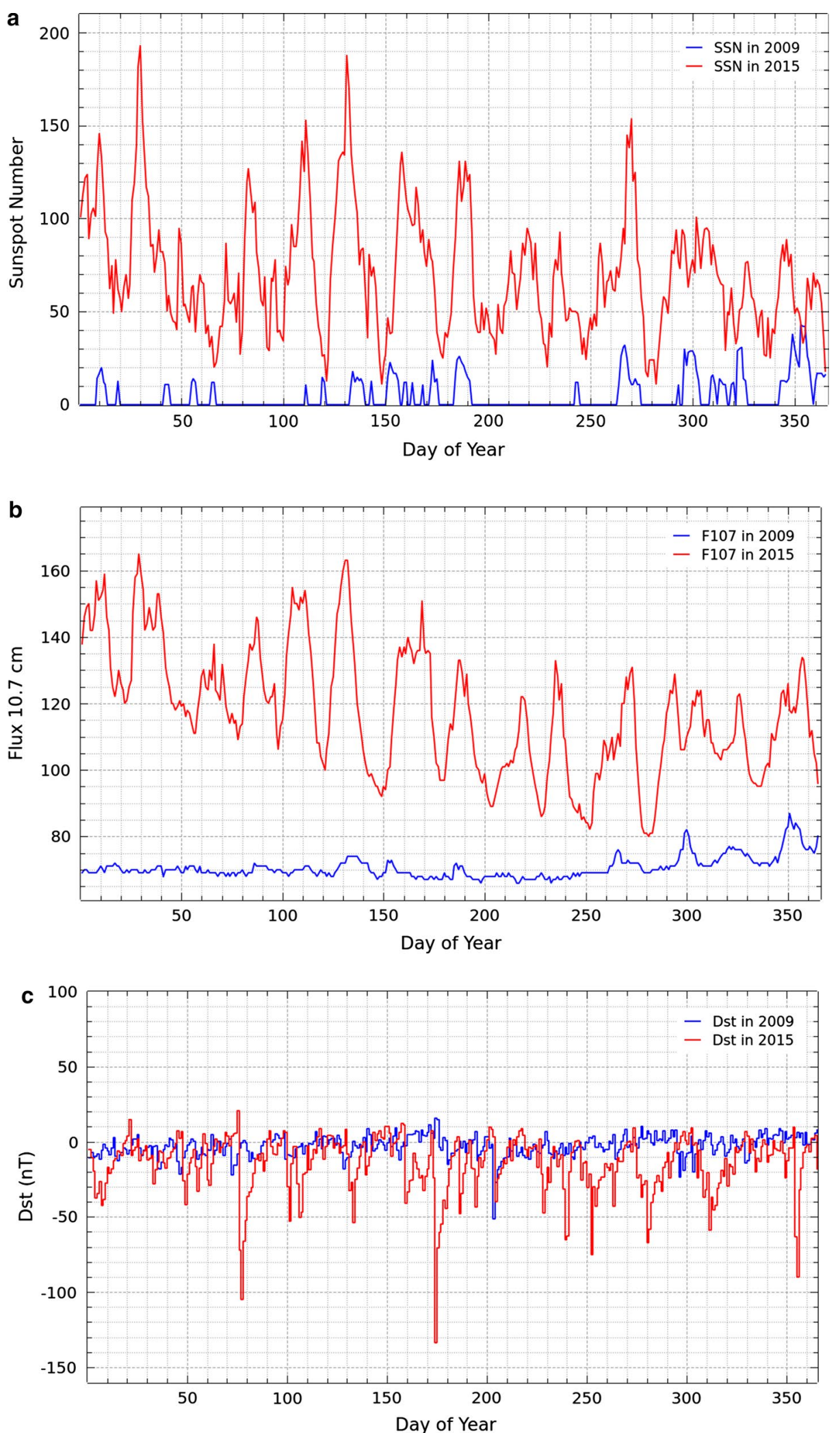

Fig. 2 SSN, F10.7, and Dst values in 2009 and 2015 are presented by the blue and red lines, respectively. a Sunspot numbers. b Solar flux at $10.7 \mathrm{~cm}$. c Dst index 


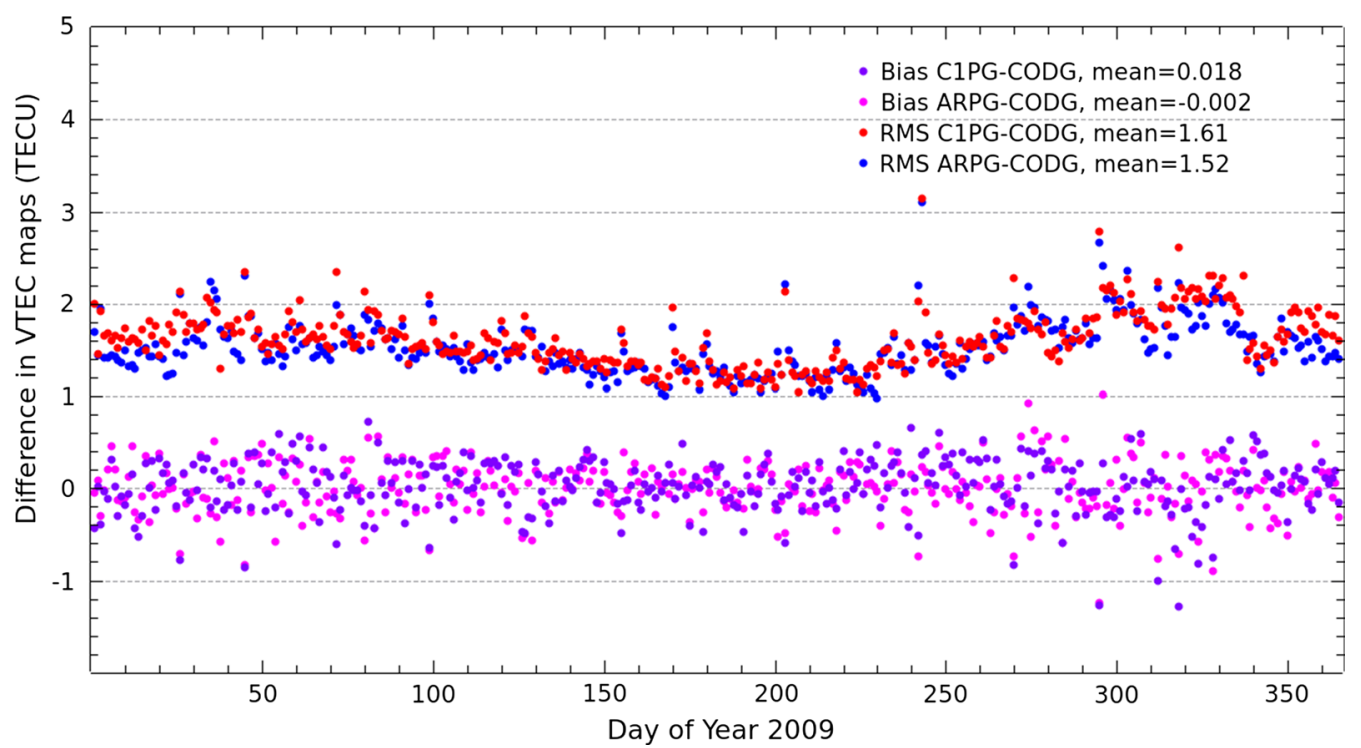

Fig. 3 Statistics of the differences in forecasting VTEC values (C1PG and ARPG) and final CODE VTEC values in 2009. The bias and RMS values of the differences are indicated by dots of different colors

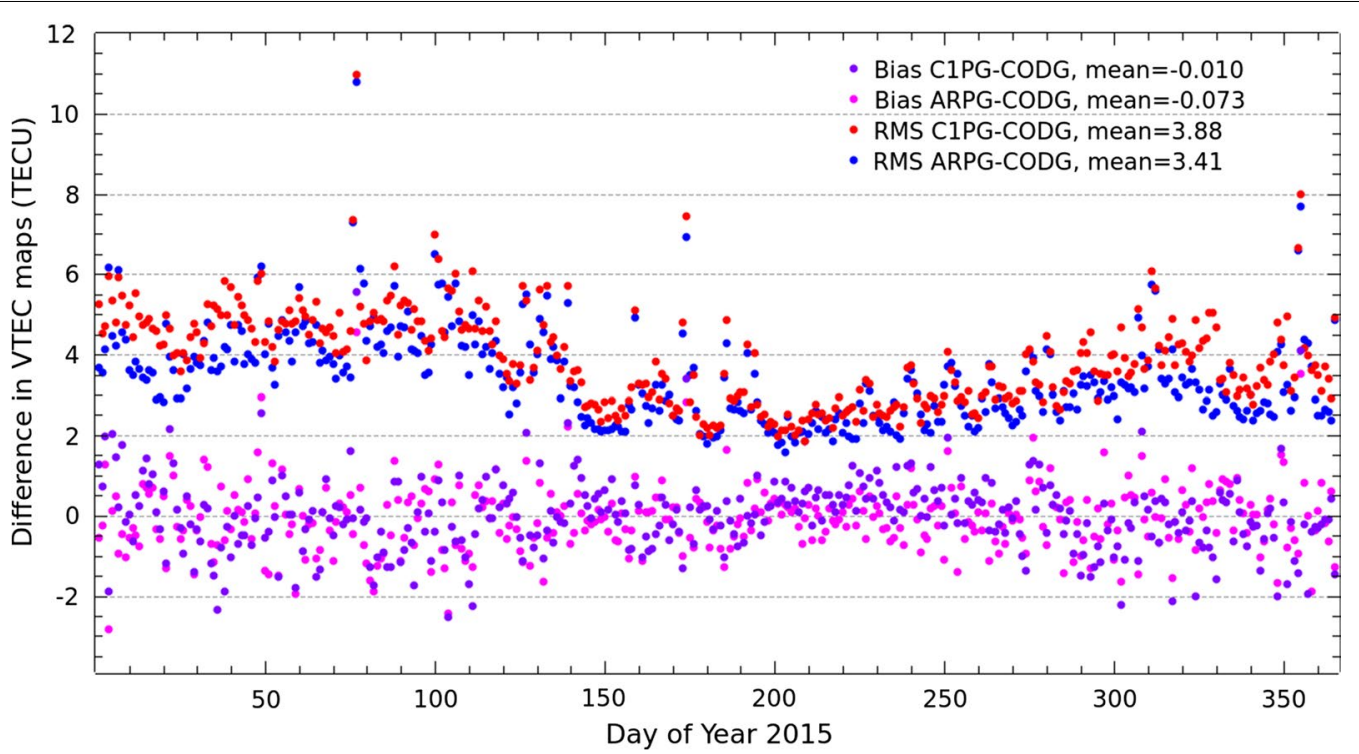

Fig. 4 Statistics of the differences in forecasting VTEC values (C1PG and ARPG) and final CODE VTEC values in 2015. The bias and RMS values of the differences are indicated by dots of different colors

that both ARPG and C1PG have no apparent systematic bias compared to CODG. In addition, the narrower distribution range of bias is within \pm 1 TECU in 2009, in contrast to 2015, which exhibited a range within \pm 2 TECU. The RMS values shown in Figs. 3 and 4 indicate that there is better consistency between ARPG and CODG, especially during spring, late autumn, and winter in 2015. Compared to C1PG in 2009, the annual mean of the RMS values by the AARM solution is approximately
0.1 TECU lower and amounts to 1.52 TECU, while in 2015, the same value is approximately 0.5 TECU lower than that of C1PG. Additionally, Table 1 (unit: TECU) presents the minimum, maximum, and mean values of bias and RMS values of the differences between forecasting VTEC values and final CODE VTEC values in 2009 and 2015. As shown in the RMS values presented in Table 1, ARPG has a slightly better forecasting performance than C1PG both in 2009 and 2015. However, 
Table 1 Minimum, maximum, and mean values of bias and RMS values of the differences between forecasting VTEC values and final CODE VTEC values in 2009 and 2015

\begin{tabular}{|c|c|c|c|c|c|c|}
\hline & \multicolumn{3}{|l|}{2009} & \multicolumn{3}{|l|}{2015} \\
\hline & Min & Max & Mean & Min & Max & Mean \\
\hline \multicolumn{7}{|l|}{ Bias } \\
\hline CIPG & -1.28 & 0.72 & 0.02 & -2.53 & 5.57 & -0.01 \\
\hline ARPG & -1.25 & 1.02 & 0.00 & -2.82 & 4.56 & -0.07 \\
\hline \multicolumn{7}{|l|}{ RMS } \\
\hline C1PG & 1.03 & 3.14 & 1.61 & 1.86 & 10.96 & 3.88 \\
\hline ARPG & 0.97 & 3.10 & 1.52 & 1.57 & 10.78 & 3.41 \\
\hline
\end{tabular}

it should be noted that the performance of forecasting depends on the season. As presented in Figs. 3 and 4 , the dispersion in the daily bias values in summer and early autumn are smaller than those in spring and winter. Additionally, the RMS values in summer are smaller than those in spring and winter, except for several days on which a magnetic storm occurred in 2015. The winter anomaly in the high solar activity period would be the higher thermospheric $\mathrm{O} / \mathrm{N}_{2}$ ratio in the winter months compared to that in the summer months (Bhuyan and Borah 2007). The $\mathrm{O} / \mathrm{N}_{2}$ ratio will be maximized at the equinox, resulting in higher electron density; thus, the equinox TEC will be higher (Bagiya et al. 2009). The thermospheric neutral composition has direct control on the seasonal variations of TEC. The meridional wind changes the neural composition and $\mathrm{O} / \mathrm{N}_{2}$ ratio (Olwendo et al. 2013). These observations may explain the seasonal variation in the differences between forecasting ionospheric products and the final CODE GIMs. Additionally, both RMS values and absolute values of daily bias values in 2015 are much larger than those in 2009. This result indicates that the performance of ionospheric forecasting depends significantly on solar activity. Furthermore, it is also dependent on geomagnetic activity. Corresponding to the Dst indices of approximately - $100 \mathrm{nT}$, as shown in Fig. 2, there are three RMS values (on DOY 77, 174, and 355) that are obviously larger than adjacent values. Therefore, it is not easy to forecast ionospheric VTEC maps with high accuracy during geomagnetic storms.

\section{Latitudinal behavior}

The latitudinal distribution of the forecasting performance is also investigated for ARPG as well as C1PG in 2009 and 2015. The latitudinal behavior of forecasting ionospheric products is analyzed by comparing forecasted VTEC values with final CODG VTEC values at the same latitude in TECU units. In Fig. 5, the daily bias of the differences between ARPG as well as C1PG and CODG is depicted. In 2009, the bias of the differences

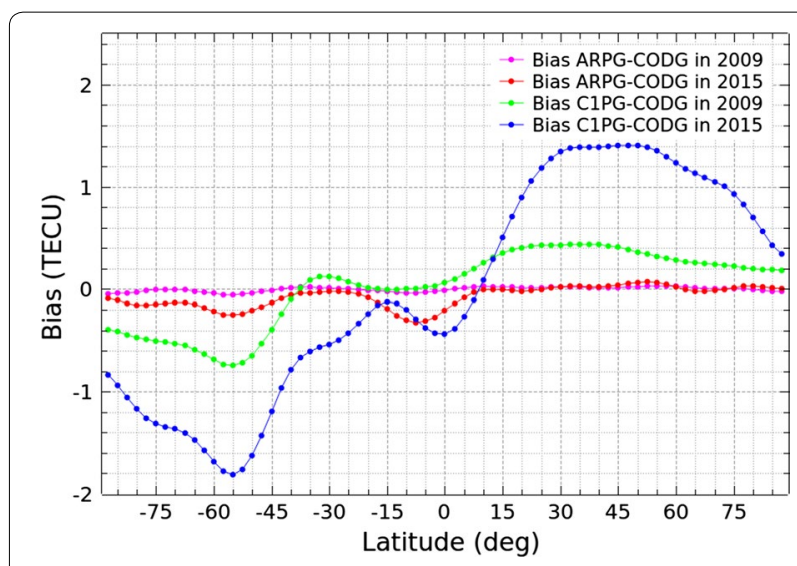

Fig. 5 Bias of the differences between forecasting products and the final CODG in 2009 and 2015. The magenta and red dotted lines depict the bias between ARPG and CODG in 2009 and 2015, respectively. The green and blue dotted lines depict the bias between C1PG and CODG in 2009 and 2015, respectively

between ARPG and CODG is almost zero TECU. The bias is also approximately zero TECU in 2015, except in some southern latitudes and the equatorial anomaly region, while the bias of the differences between C1PG and CODG fluctuates significantly with latitude, especially in 2015. With respect to CODG, the C1PG solution overestimates VTEC values below 1 TECU in northern latitudes and underestimates those with a maximum of approximately 2 TECU in southern latitudes. Figure 6 presents the RMS values of the differences between forecasting products and CODG in 2009 and 2015. As seen, structures similar to those in TEC values in the EIA region appear in both 2009 and 2015. These structures are more pronounced in mid-to-high solar activity periods than in low solar activity periods. Therefore, it is hard to predict VTEC values accurately in the EIA region. The RMS values at solar minimum in 2009 are within 1-2 TECU, which is much less than the 3-6 TECU from 2015. Additionally, most RMS values of differences 


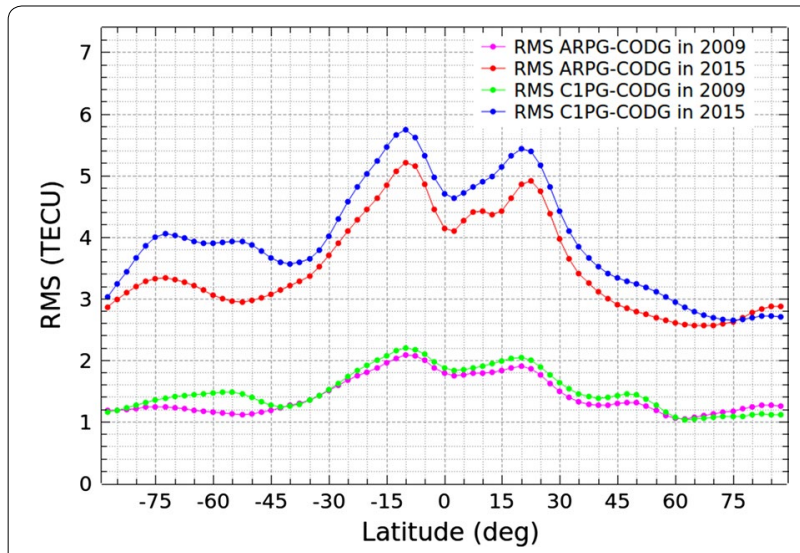

Fig. 6 RMS of the differences between forecasting products and the final CODG in 2009 and 2015. The magenta and green dotted lines depict the RMS of the differences between ARPG and CODG and those between C1PG and CODG in 2009, respectively. Red and blue dotted lines depict the RMS of the differences between ARPG and CODG and those between C1PG and CODG in 2015, respectively between ARPG and CODG are smaller than those of differences between C1PG and CODG, especially in southern mid- and high latitudes.

Another comparison is performed to investigate the performance of the proposed algorithm for forecasting VTEC maps both in 2009 and 2015. The two solutions for providing ARPG with and without an $F$ test are conducted. One is based on AR modeling with a fixed order of 60 . The order for the other solution is adaptively determined by an $F$ test, as mentioned in "Basic methodology of ionospheric forecasting" section. Figure 7 presents the differences between ARPG with and without an $F$ test and CODG, respectively. As shown in Fig. 7a, the fluctuation of bias without an $F$ test is higher than that with an $F$ test in the Southern Hemisphere. Additionally, the bias with an $F$ test is lower than that without an $F$ test in the high latitudes of the Northern Hemisphere. The performances of the two solutions seem similar with respect to bias in 2015, except in the mid-low latitudes and high
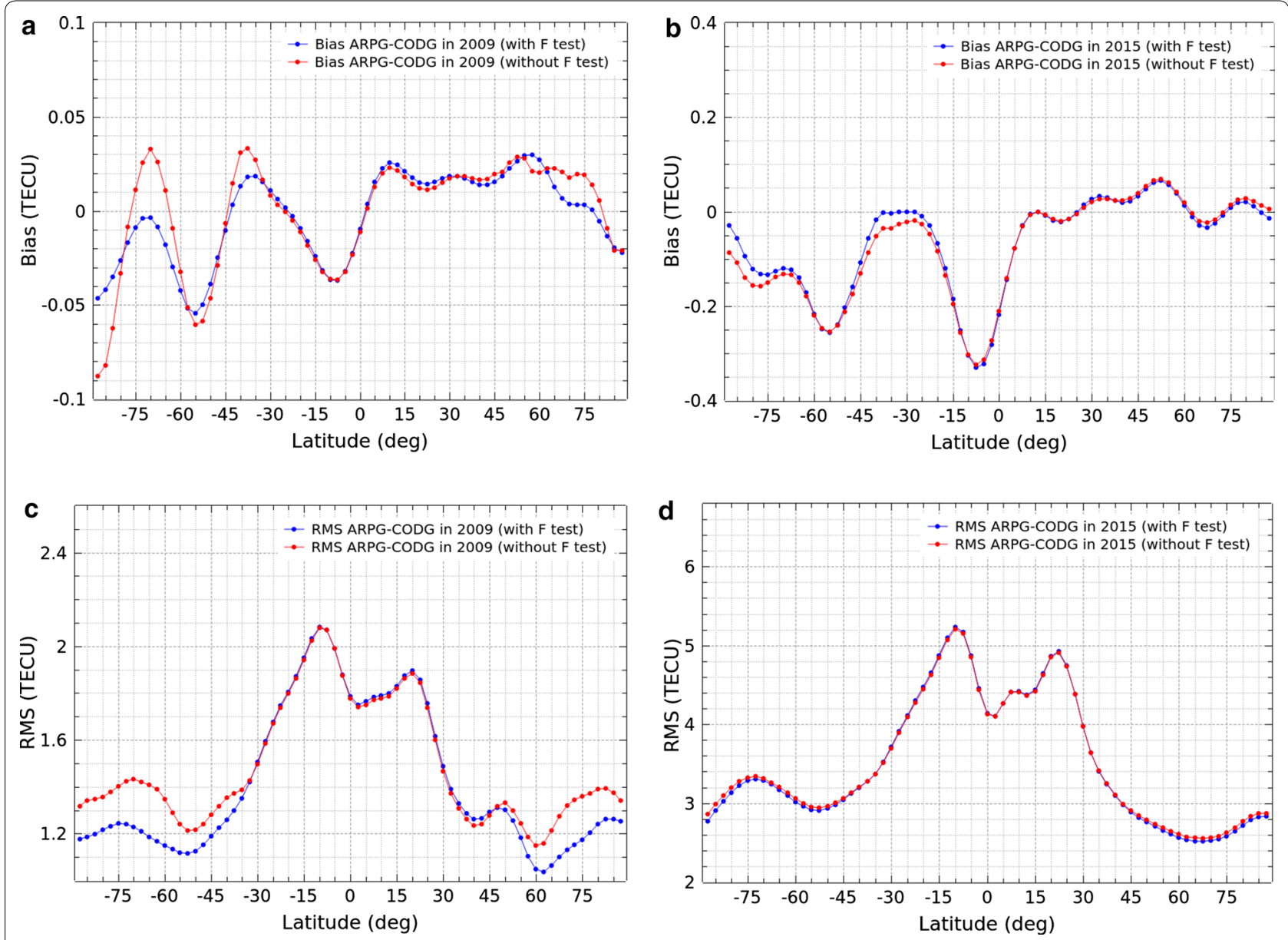

Fig. 7 Bias and RMS of the differences between forecasting products ARPG and the final CODG in 2009 and 2015. The blue and red dotted lines depict the differences between ARPG with and without an F test and CODG, respectively. a Bias of ARPG minus CODG in 2009. b Bias of ARPG minus CODG in 2015. c RMS of ARPG minus CODG in 2009. d RMS of ARPG minus CODG in 2015 
latitudes of the Southern Hemisphere. Additionally, as presented in Fig. 7c, the RMS values without an $F$ test are larger than those with an $F$ test in the middle and high latitudes of the Southern Hemisphere, as well as in the mid-high latitudes and high latitudes of the Northern Hemisphere. As the RMS shown in Fig. 7d, a similar situation is presented in 2015. In general, the performance of ARPG with an $F$ test is better than that of ARPG without an $F$ test.

\section{Latitudinal and longitudinal behavior}

In this section, the geographic distribution of the performance of VTEC map forecasting is investigated at the level of a grid point. Figures 8 and 9 present the maps showing the bias and RMS of the differences between forecasting VTEC maps (including ARPG and C1PG) and CODG in 2009 and 2015, and the sub-figures show the differences between ARPG, C1PG, and CODG, respectively. In these figures, the units of both latitude and longitude are degrees, and the units of both bias and RMS values are TECU.

As shown in Fig. 8a, the bias in 2009 all over the world is approximately zero TECU. In Fig. 8b, the geographic distribution of bias is more uneven than that in Fig. 8a. Additionally, the bias is mostly positive in the Northern Hemisphere and negative in the middle and high latitudes of the Southern Hemisphere. Additionally, the range of bias values between forecasting products and CODG in 2015 is much larger than those in 2009. This result may be due to the higher solar activity in 2015 . Additionally, it should be noted that the biases between C1PG and CODG are obviously different in the Northern Hemisphere and Southern Hemisphere. C1PG overestimates VTEC values by more than 2 TECU in the Northern Hemisphere, in contrast to the underestimation of approximately 2 TECU that occurs in the Southern Hemisphere, except in some areas of both low latitude and low longitude. This phenomenon is also shown in Fig. 5, which shows the latitudinal distribution of the bias. Figure 8 indicates that C1PG-predicted VTEC maps exhibit apparent systematic error both in 2009 and 2015.

Figure 9 presents the differences between forecasting VTEC maps and CODG in terms of RMS values in 2009 and 2015, respectively. All sub-figures show that RMS values in the EIA area are higher than those in other areas, particularly in 2015. During the solar minimum, both C1PG and ARPG have good consistency with the final CODG in terms of RMS values, which are less than 3 TECU, while in 2015, the highest RMS values are approximately $8 \mathrm{TECU}$ in the EIA area. Furthermore, Fig. 9 shows that the forecast performance of ARPG is better than that of C1PG in the EIA area and the Southern Hemisphere, especially in 2015.

The globe is divided into three latitudinal bands: the northern band $\left(32.5^{\circ}-87.5^{\circ}\right)$, the middle band $(-32.5-$ $\left.32.5^{\circ}\right)$, and the southern band $\left(-87.5^{\circ}\right.$ to $\left.-32.5^{\circ}\right)$, to investigate the specific differences between forecasting VTEC maps and the final CODG. The annual means of
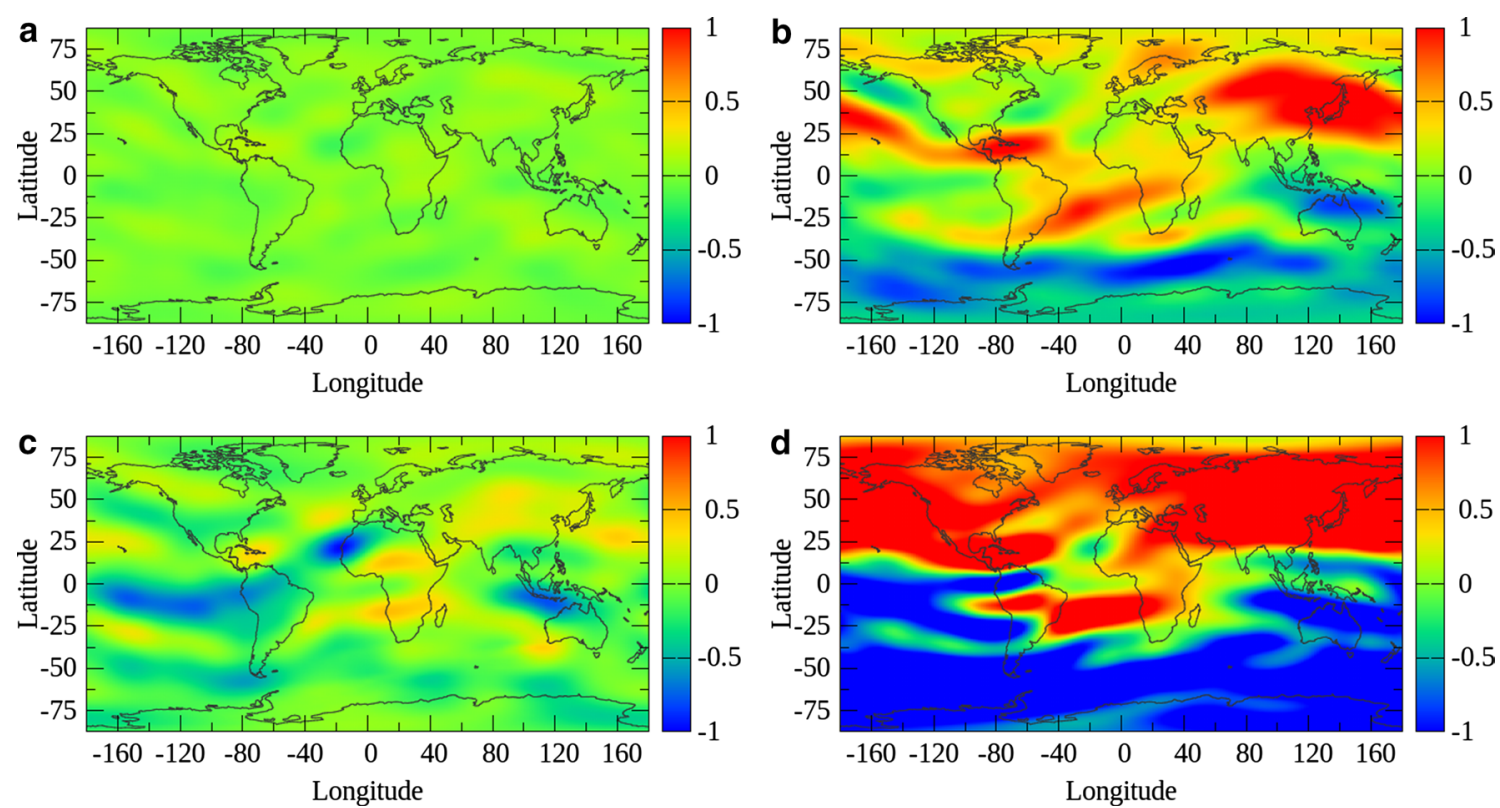

Fig. 8 Bias of the differences between forecasting products ARPG and C1PG, and the final CODG product in 2009 and 2015. a Bias of ARPG minus CODG in 2009. b Bias of C1PG minus CODG in 2009. c Bias of ARPG minus CODG in 2015. d Bias of C1PG minus CODG in 2015 

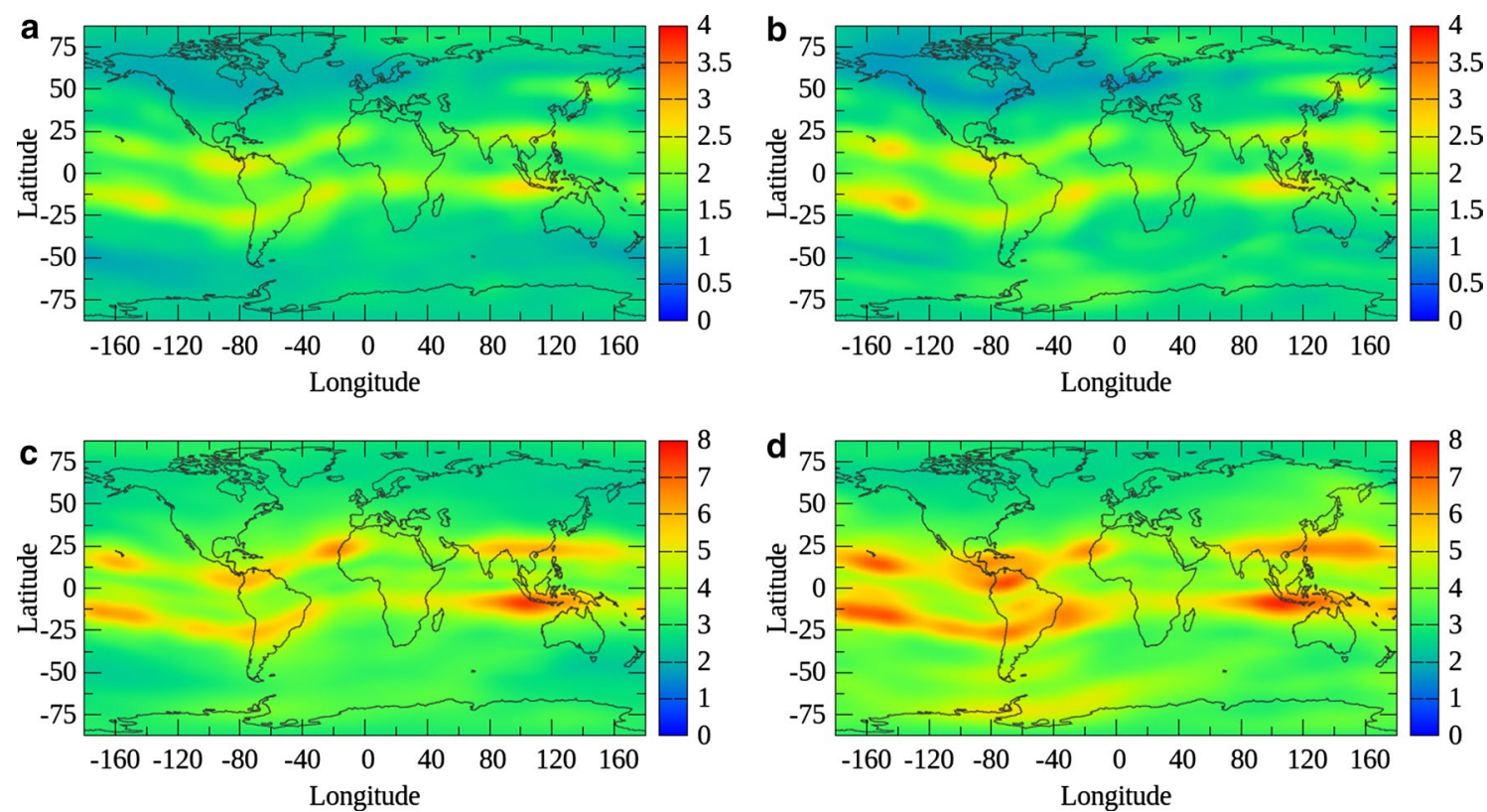

Fig. 9 RMS values of the differences between forecasting products ARPG and C1PG, and the final CODG product in 2009 and 2015. a RMS of ARPG minus CODG in 2009. b RMS of C1PG minus CODG in 2009. c RMS of ARPG minus CODG in 2015. d RMS of C1PG minus CODG in 2015

the daily bias and RMS values for the 3 bands are shown in Table 2 (unit: TECU). From the bias given in Table 2, the difference between C1PG and CODG is apparently larger than that between ARPG and CODG both in 2009 and 2015. Additionally, the RMS values presented in Table 2 indicate that there is better consistency between ARPG and CODG, especially in 2015. Moreover, RMS values for the middle band are larger than those for the northern band and southern band both in 2009 and 2015. Figure 9 also depicts this phenomenon.

\section{Validation with JASON data}

J2TEC, as an external independent dataset mentioned in "Test and reference data" section, is used to evaluate the accuracy of the predicted ionospheric VTEC maps over oceans and southern latitudes. The comparison of VTEC values between the final GIM VTEC values (including CODG and IGSG) and J2TEC is also investigated to provide a reference. The numbers of available J2TEC over different latitudes in the year 2009 and 2015 are shown in Fig. 10. It depicts that there is much more JASON data over the Southern Hemisphere than over the Northern Hemisphere, because there is more land in the Northern Hemisphere, while the JASON data only contains observations over oceans. Figures 11 and 12 show the bias and RMS values between forecasting VTEC maps, final GIMs, and J2TEC in 2009 and 2015, respectively.

As shown in Fig. 11, the absolute values of bias in low latitudes are smaller than those in mid-high latitudes. Both forecasting VTEC maps and final GIMs are smaller

Table 2 Bias and RMS values of the differences between forecasting VTEC values and final CODE VTEC values in 2009 and 2015, in TECU

\begin{tabular}{|c|c|c|c|c|c|c|}
\hline & \multicolumn{3}{|l|}{2009} & \multicolumn{3}{|l|}{2015} \\
\hline & North & Middle & South & North & Middle & South \\
\hline \multicolumn{7}{|l|}{ Bias } \\
\hline CIPG & 0.34 & 0.18 & -0.44 & 1.10 & 0.12 & -1.28 \\
\hline ARPG & 0.0034 & 0.0020 & -0.013 & 0.022 & -0.093 & -0.15 \\
\hline \multicolumn{7}{|l|}{ RMS } \\
\hline C1PG & 1.31 & 1.90 & 1.48 & 3.04 & 4.95 & 3.76 \\
\hline ARPG & 1.32 & 1.79 & 1.37 & 2.80 & 4.44 & 3.14 \\
\hline
\end{tabular}




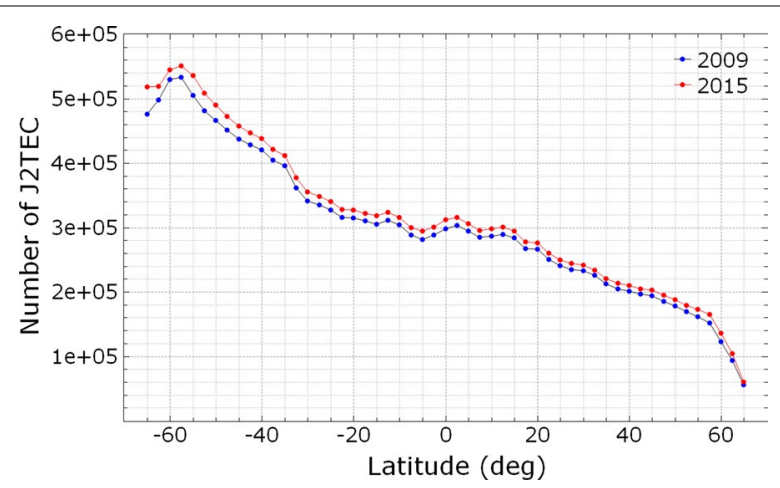

Fig. 10 Number of available J2TEC over different latitudes in 2009 and 2015 than JASON VTEC values, especially in mid-high latitudes. Other studies also obtained the same results, in which JASON VTEC values are larger than the VTEC values derived from GNSS measurements (Mandrake et al. 2005; Hernández-Pajares et al. 2009; García-Rigo et al. 2011). However, the possible reasons for this fact are not clear yet and should be investigated in the future. Additionally, Fig. 11 depicts that ARPG has almost the same performance as CODG. Meanwhile in 2015, GIMs are larger than JASON VTEC values in low and mid-low latitudes and smaller than those in other latitudes. ARPG also has a similar performance to CODG in 2015. Moreover, RMS values of the differences between forecasting
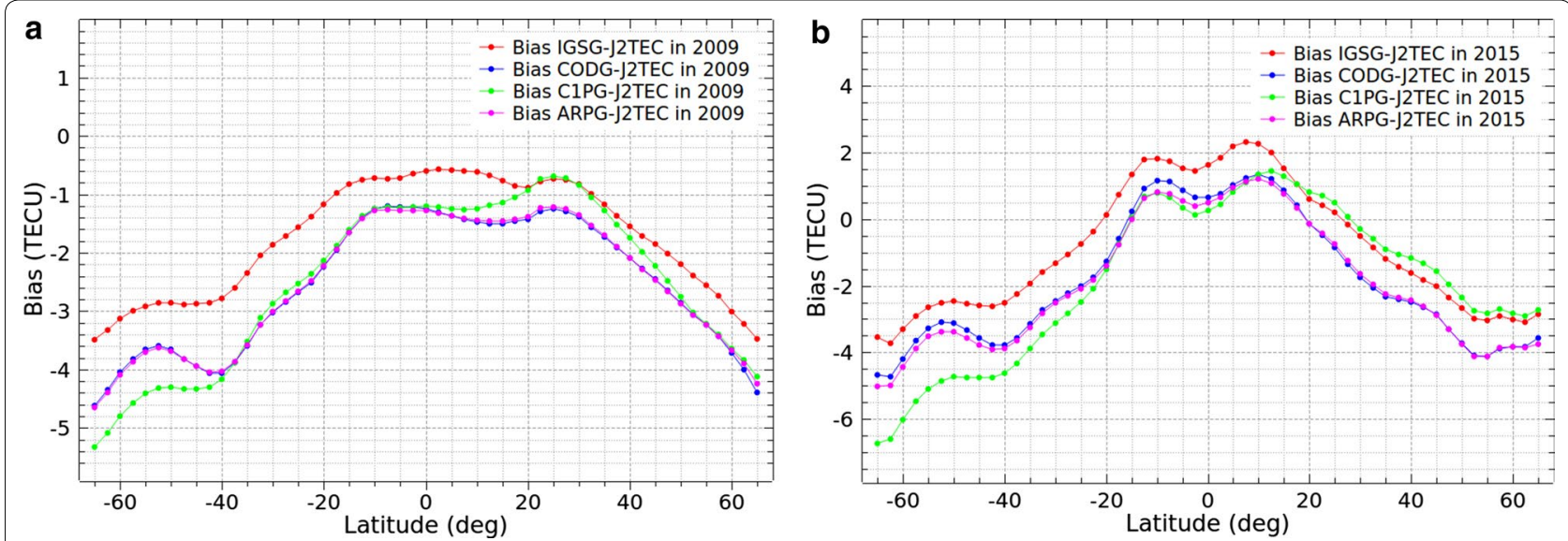

Fig. 11 Bias of the differences between forecasting VTEC maps, final GIMs, and J2TEC in 2009 and 2015. The red, blue, green, and magenta dotted lines depict the bias of the final IGS GIMs, the final CODE GIMs, the CODE forecasting VTEC maps, and forecasting products by proposed adaptive AR model, respectively, compared to VTEC values derived from JASON data. a Bias of VTEC maps minus J2TEC in 2009. b Bias of VTEC maps minus J2TEC in 2015
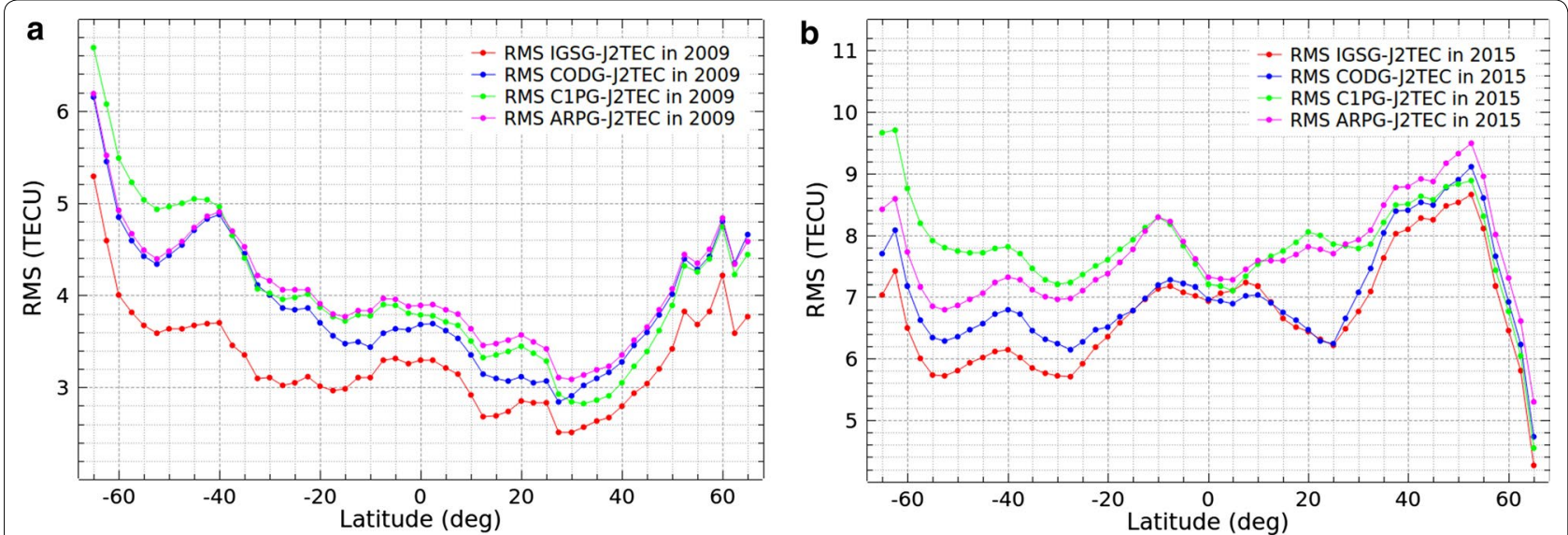

Fig. 12 RMS of the differences between forecasting VTEC maps, final GIMs, and J2TEC in 2009 and 2015. The red, blue, green, and magenta dotted lines depict the RMS of differences between the final IGS GIMs, the final CODE GIMs, the CODE forecasting VTEC maps, and forecasting products by proposed adaptive AR model, respectively, and the VTEC values derived from JASON data. a RMS of VTEC maps minus J2TEC in 2009. b RMS of VTEC maps minus J2TEC in 2015 
VTEC maps, final GIMs, and J2TEC in 2009 show a similar trend, as presented in Fig. 12. Compared to J2TEC, the final GIMs (including CODG and IGSG) show better consistency than the forecasting VTEC maps, and this behavior is more obvious in the mid-high latitudes of the Southern Hemisphere in 2009, as well as in both the low latitudes of the Northern Hemisphere and the mid-high latitudes of the Southern Hemisphere in 2015. Therefore, the performance of forecasting products is not as good in mid-high solar activity as they are in low solar activity, particularly in EIA areas and the Southern Hemisphere.

Overall, the final IGS GIMs have the best consistency with JASON data among the forecasting VTEC maps and final GIMs. Since there are few GNSS measurements over ocean areas and the Southern Hemisphere, VTEC maps provided by IAACs might have low accuracy over these areas. From the bias presented in Fig. 11, the forecasting ARPG VTEC maps perform similarly as the final CODE GIMs. With respect to bias, it seems that C1PG has good performance in the Northern Hemisphere, sometimes even better than IGSG. According to the results in "Latitudinal behavior" and "Latitudinal and longitudinal behavior" sections, which indicate that C1PG has apparent systematic error both in 2009 and 2015, C1PG provides overestimated VTEC values in the northern latitudes and underestimated VTEC values in the southern latitudes. Therefore, there is reason to believe that it is just a coincidence that the performance of C1PG is better than that of CODG in mid- and high latitudes both in 2009 and 2015, especially even better than IGSG in the mid- and high latitudes in 2015. From the RMS values presented in Fig. 12, ARPG has similar performance to CODG in 2009, but not as good in 2015, especially in the EIA area and the Southern Hemisphere.

\section{Discussion}

From the comparative results presented above, the forecasting VTEC maps derived by the proposed adaptive AR model perform better than CODE's forecasting product when comparing with final CODE GIMs. The performance of C1PG is not as good as that of ARPG, especially during periods of mid-to-high solar activity. There might be two reasons for this problem. On the one hand, it might be inappropriate to extrapolate the $\mathrm{SH}$ coefficients by using the least-squares collocation method. The periodic features of $\mathrm{SH}$ coefficients should be well known before using the LSC method. So far, the periodic features of VTEC are known quite well, e.g., the periods of $11,1,1 / 2$ year, 14.77 days, and 1 solar day. SH coefficients have no obvious physical significance because they are estimated mathematically by the least-squares method. Therefore, although VTEC is represented by the linear combination of $\mathrm{SH}$ coefficients, the periodic features of $\mathrm{SH}$ coefficients might not be the same as those of VTEC values. ARPG is derived from the extrapolated $\mathrm{SH}$ coefficients, calculated by using the proposed adaptive AR model. The AARM method does not involve the specific periodic features of $\mathrm{SH}$ coefficients. Rather, the AARM method reflects the features of $\mathrm{SH}$ coefficients to describe the relationship between current and historical $\mathrm{SH}$ coefficients, while C1PG is derived from the extrapolated SH coefficients considered by CODE to have the same periodic features of VTEC values. Additionally, the VTEC could present a more complex variation during periods of mid-to-high solar activity. It is possible that C1PG has even larger errors in 2015, as shown in Figs. 8 and 9. On the other hand, the forecasting ionospheric products C1PG are generated in an operational environment, in contrast to ARPG, estimated by postprocessing. Thus, the performance of ARPG might worsen in an operational environment of providing daily forecasting products.

\section{Conclusions}

An improved algorithm is proposed for the short-term prediction of global ionospheric VTEC maps. A time series of SH coefficients from the previous 30 days is constructed and used to perform autoregressive modeling to predict SH coefficients. Global ionospheric forecasting VTEC maps are generated from the predicted SH coefficients. Comparisons and validations are conducted to assess the performance of the forecasting VTEC maps. Results show that the forecasting ionospheric products from CODE (C1PG) have an apparent systematic error of greater than 1 TECU, especially in areas with mid-tohigh solar activity. ARPG performs similarly as the final CODE GIMs (CODG), such that no apparent systematic error is detected. ARPG shows better consistency with CODG than C1PG, especially in southern mid- and high latitudes. Additionally, independent VTEC data from JASON are collected to evaluate the performance of forecasting products over ocean areas. A good agreement between the final IGS GIMs and JASON data is found, and the RMS of their difference is approximately 3 TECU and greater than 6 TECU in low solar activity and midto-high solar activity, respectively.

However, the methods for forecasting products from CODE, ESA, and UPC, as well as ARPG, presented in this manuscript are actually based on mathematical fitting without consideration of the physical processes. "Comparison of predicted VTEC maps" section shows that the performance of forecasting ionospheric VTEC maps was limited during geomagnetic storms on DOY 77, 174, and 355 in 2015. The main reason might be that the AARM model could not adapt to the sudden change in geomagnetic activity. On the other hand, the accuracy of the final 
VTEC maps might be lower during geomagnetic storms. Additionally, limited data availability and inhomogeneous distribution of GNSS stations could also impact the performance of forecasting. Therefore, a key priority for the prediction of global ionospheric VTEC maps in the future should be importing physical information in terms of solar and geomagnetic activities, such as the solar flux and Dst.

In general, the final CODE products of $\mathrm{SH}$ coefficients have been used to forecast VTEC maps in this study, while in an operational environment, the forecasting should require SH coefficients of the recent days in a short period of time. WHU has planned to generate ultra-rapid ionospheric products with a latency of $2 \mathrm{~h}$. By then, forecasting VTEC maps using ultra-rapid $\mathrm{SH}$ coefficients might be a valid approach to understand the real-time applicability of the proposed method. Like the final combined IGS GIMs that partially filter systematic errors with the combination process (Orús et al. 2005; García-Rigo et al. 2011), combined IGS predicted products could also have improved performance in the future.

\section{Authors' contributions}

CW proposed the research topic, developed the algorithm, and wrote the main manuscript text; CS and SX designed the experiment and checked the final results; $X L$ and FL have contributed to writing and improving the paper. All authors read and approved the final manuscript.

\section{Author details \\ ${ }^{1}$ Collaborative Innovation Center for Geospatial Information Technology, No. 129 Luoyu Road, Wuhan 430079, China. ${ }^{2}$ School of Electronic Information Engineering, Beihang University, No. 37 Academic Road, Beijing 100083, China ${ }^{3}$ School of Geodesy and Geomatics, Wuhan University, No. 129 Luoyu Road, Wuhan 430079, China. ${ }^{4}$ Shanghai Urban Construction Design and Research Institute, No. 3722 Dongfang Road, Pudong New Area, Shanghai 200125, China.}

\section{Acknowledgements}

The authors appreciate CODE for providing SH coefficients and final ionospheric products. Also, the authors would like to thank IGS for final GIMs and NASA/CNES for JASON data. The authors would like to thank the anonymous reviewers and the editor for their comments and useful suggestions, which have been very helpful in revising the manuscript. This study has been funded by the National Key Research and Development Program of China (No. 2016YFB0501802), the Fundamental Research Funds for the Central Universities (No. 2042016kf0061) and the National Natural Science Foundation of China (No. 41274049), as well as by the China Postdoctoral Science Foundation (No. 2016M600613).

\section{Competing interests}

The authors declare that they have no competing interests.

\section{Ethics approval and consent to participate}

Not applicable.

\section{Publisher's Note}

Springer Nature remains neutral with regard to jurisdictional claims in published maps and institutional affiliations.

Received: 7 February 2017 Accepted: 12 December 2017 Published online: 02 February 2018

\section{References}

Abdu M, Batista I, De Souza J (1996) An overview of IRI-observational data comparison in American (Brazilian) sector low latitude ionosphere. Adv Space Res 18(6):13-22

Adewale A, Oyeyemi E, Adeniyi J, Adeloye A, Oladipo O (2011) Comparison of total electron content predicted using the IRI-2007 model with GPS observations over Lagos, Nigeria. Indian J Radio Space Phys 40(1):21-25

Araujo-Pradere E, Fuller-Rowell T, Bilitza D (2003) Validation of the STORM response in IRI2000. J Geophys Res Space Phys 108(A3). https://doi. org/10.1029/2002JA009720

Bagiya MS, Joshi H, Iyer K, Aggarwal M, Ravindran S, Pathan B (2009) TEC variations during low solar activity period (2005-2007) near the equatorial ionospheric anomaly crest region in India. Ann Geophys 27(3):1047-1057

Bertoni F, Sahai Y, Lima W, Fagundes P, Pillat V, Becker-Guedes F, Abalde J (2006) IRI-2001 model predictions compared with ionospheric data observed at Brazilian low latitude stations. Ann Geophys 24(8):2191-2200

Bhuyan P, Borah RR (2007) TEC derived from GPS network in India and comparison with the IRI. Adv Space Res 39(5):830-840

Bilitza D, Reinisch BW (2008) International reference ionosphere 2007: improvements and new parameters. Adv Space Res 42(4):599-609

Bilitza D, McKinnell L-A, Reinisch B, Fuller-Rowell T (2011) The international reference ionosphere today and in the future. J Geodesy 85(12):909-920

Blackwell M (2008) Multiple hypothesis testing: the F-test. Matt Blackwell Research, Oxford

Bouya Z, Terkildsen M, Neudegg D (2010) Regional GPS-based ionospheric TEC model over Australia using spherical cap harmonic analysis. COSPAR Scientific Assembly

Chen Z, Zhang SR, Coster AJ, Fang G (2015) EOF analysis and modeling of GPS TEC climatology over North America. J Geophys Res Space Phys 120(4):3118-3129

Cheng $\mathrm{H}$ (1982) Autoregressive modeling and causal ordering of economic variables. J Econ Dyn Control 4(3):243-259

Costa AH, Hengstler S (2011) Adaptive time-frequency analysis based on autoregressive modeling. Sig Process 91(4):740-749

De Franceschi G, Zolesi B (1998) Regional ionospheric mapping and modelling over Antarctica. Ann Geophys 41(5-6):813-818

Dow JM, Neilan R, Rizos C (2009) The international GNSS service in a changing landscape of global navigation satellite systems. J Geodesy 83(3-4):191-198

Ercha A, Zhang D, Ridley AJ, Xiao Z, Hao Y (2012) A global model: Empirical orthogonal function analysis of total electron content 1999-2009 data. J Geophys Res Atmos 117(A3):3328

Faul F, Erdfelder E, Buchner A, Lang A-G (2009) Statistical power analyses using $G^{*}$ Power 3.1: tests for correlation and regression analyses. Behav Res Methods 41(4):1149-1160

Fisher RA (1925) Statistical methods for research workers. Genesis Publishing Pvt Ltd, Guildford

Fuller-Rowell T, Araujo-Pradere E, Minter C, Codrescu M, Spencer P, Robertson D, Jacobson AR (2016) US-TEC: A new data assimilation product from the Space Environment Center characterizing the ionospheric total electron content using real-time GPS data. Radio Sci 41(6):1-8

García-Rigo A, Monte E, Hernández-Pajares M, Juan JM, Sanz J, Aragón-Angel A, Salazar D (2011) Global prediction of the vertical total electron content of the ionosphere based on GPS data. Radio Sci 46(6)

Gu X, Jiang J (2005) A complex autoregressive model and application to monthly temperature forecasts. Ann Geophys 23(10):3229-3235

Habarulema JB, McKinnell L-A, Opperman BD (2010) TEC measurements and modelling over Southern Africa during magnetic storms; a comparative analysis. J Atmos Solar-Terr Phys 72(5):509-520

Hamilton JD (1994) Time series analysis. Princeton University Press, Princeton

Harrell F (2015) Regression modeling strategies: with applications to linear models, logistic and ordinal regression, and survival analysis. Springer, Berlin

Hernández-Pajares M, Juan J, Sanz J (1999) New approaches in global ionospheric determination using ground GPS data. J Atmos Solar Terr Phys 61(16):1237-1247

Hernández-Pajares M, Juan J, Sanz J, Orus R, Garcia-Rigo A, Feltens J, Komjathy A, Schaer S, Krankowski A (2009) The IGS VTEC maps: a reliable source of ionospheric information since 1998. J Geodesy 83(3-4):263-275 
Huang L, Zhang H, Xu P, Geng J, Wang C, Liu J (2017) Kriging with unknown variance components for regional ionospheric reconstruction. Sensors 17(3):468

Karthik P, Ratnam DV, Vanga N, Brahmanadam P, Rao BSS, Kumar KS (2012) Auto regressive ionospheric prediction model for GPS applications. Int $J$ Comput Appl 48(4):7-9

Klobuchar J (1987) Ionospheric time-delay algorithm for single-frequency GPS users. IEEE Trans Aerosp Electron Syst 3:325-331

Komjathy A (1997) Global ionospheric total electron content mapping using the global positioning system, University of New Brunswick

Krankowski A, Kosek W, Baran LW, Popinski W (2005) Wavelet analysis and forecasting of VTEC obtained with GPS observations over European latitudes. J Atmos Solar Terr Phys 67(12):1147-1156

Labovitz S (1968) Criteria for selecting a significance level: a note on the sacredness of .05. Am Sociol 3(3):220-222

Lee C-C, Reinisch BW (2006) Quiet-condition hmF2, NmF2, and B 0 variations at Jicamarca and comparison with IRI-2001 during solar maximum. J Atmos Solar Terr Phys 68(18):2138-2146

Lee CY, Tippett MK, Sobel AH, Camargo SJ (2016) Autoregressive modeling for tropical cyclone intensity climatology. J Clim 29(21):7815-7830. https:// doi.org/10.1175/JCLI-D-15-0909.1

Mandrake L, Wilson B, Wang C, Hajj G, Mannucci A, Pi X (2005) A performance evaluation of the operational Jet Propulsion Laboratory/University of Southern California global assimilation ionospheric model (JPL/USC GAIM). J Geophys Res Space Phys 110(A12). https://doi. org/10.1029/2005JA011170

Mannucci A, Wilson B, Yuan D, Ho C, Lindqwister U, Runge T (1998) Global mapping technique for GPS-derived ionospheric total electron content measurements. Radio Sci 33(3):565-582

Mosert M, Gende M, Brunini C, Ezquer R, Altadill D (2007) Comparisons of IRI TEC predictions with GPS and digisonde measurements at Ebro. Adv Space Res 39(5):841-847

Muhtarov P, Kutiev I (1999) Autocorrelation method for temporal interpolation and short-term prediction of ionospheric data. Radio Sci 34(2):459-464

Mukhtarov P, Pancheva D, Andonov B, Pashova L (2013) Global TEC maps based on GNSS data: 1. Empirical background TEC model. J Geophys Res Space Phys 118(7):4594-4608

Nava B, Coïsson P, Radicella SM (2008) A new version of the NeQuick ionosphere electron density model. J Atmos Solar Terr Phys 70(15):1856-1862

Nieuwenhuis S, Forstmann BU, Wagenmakers E-J (2011) Erroneous analyses of interactions in neuroscience: a problem of significance. Nat Neurosci 14(9):1105-1107

Nigussie M, Radicella S, Damtie B, Nava B, Yizengaw E, Groves K (2013) Validation of the NeQuick 2 and IRI-2007 models in East-African equatorial region. J Atmos Solar Terr Phys 102:26-33

Okoh D, McKinnell L-A, Cilliers P, Okeke P (2013) Using GPS-TEC data to calibrate VTEC computed with the IRI model over Nigeria. Adv Space Res 52(10):1791-1797

Olwendo O, Baki P, Cilliers P, Mito C, Doherty P (2013) Comparison of GPS TEC variations with IRI-2007 TEC prediction at equatorial latitudes during a low solar activity (2009-2011) phase over the Kenyan region. Adv Space Res 52(10):1770-1779
Orús Pérez R, Hernández Pajares M, Zornoza J, Miguel J, Sanz Subirana J, Ángel A, Ángeles M, García Rigo A (2010) Real time application of Tomion model. Beacon Satellite Symposium

Orús R, Hernández-Pajares M, Juan J, Sanz J (2005) Improvement of global ionospheric VTEC maps by using kriging interpolation technique. J Atmos Solar Terr Phys 67(16):1598-1609

Radicella SM, Leitinger R (2001) The evolution of the DGR approach to model electron density profiles. Adv Space Res 27(27):35-40

Rawer K, Bilitza D, Ramakrishnan S (1978) Goals and status of the International Reference lonosphere. Rev Geophys 16(2):177-181

Rice WR (1989) Analyzing tables of statistical tests. Evolution 43(1):223-225

Risch N, Merikangas K (1996) The future of genetic studies of complex human diseases. Science 273(5281):1516-1517

Rovira-Garcia A, Juan JM, Sanz J, González-Casado G (2015) A worldwide ionospheric model for fast precise point positioning. IEEE Trans Geosci Remote Sens 53(8):4596-4604

Schaer S (1999) Mapping and predicting the earth's ionosphere using the global positioning system. Geodätisch-geophysikalische Arbeiten in der Schweiz, vol 59. Institut für Geodäsie und Photogrammetrie, Zürich

Shi C, Gu S, Lou Y, Ge M (2012) An improved approach to model ionospheric delays for single-frequency precise point positioning. Adv Space Res 49(12):1698-1708

Silvestrin P, Berger M, Kerr Y, Font J (2001) ESA's second earth explorer opportunity mission: the soil moisture and ocean salinity mission-SMOS. IEEE Geosci Remote Sens Newsl 118:11-14

Storey JD, Tibshirani R (2003) Statistical significance for genomewide studies. Proc Natl Acad Sci 100(16):9440-9445

Tulunay E, Senalp ET, Radicella SM, Tulunay Y (2006) Forecasting total electron content maps by neural network technique. Radio Sci 41(4):1-32

Wan WX, Feng D, Ren ZP, Zhang ML, Liu LB, Ning BQ (2012) Modeling the global ionospheric total electron content with empirical orthogonal function analysis. Sci China Technol Sci 55(5):1161-1168

Wang C (2016) Comparison of ionospheric characteristic parameters obtained by GPS and ionosonde with IRI model over China. J Earth Syst Sci 125(4):745-759

Wang C, Shi C, Zhang H, Fan L (2016) Improvement of global ionospheric VTEC maps using the IRI 2012 ionospheric empirical model. J Atmos Solar Terr Phys 146:186-193

Weiss J, Bernardara P, Andreewsky M, Benoit M (2012) Seasonal autoregressive modeling of a skew storm surge series. Ocean Model 47(3):41-54

Wichaipanich N, Supnithi P, Tsugawa T, Maruyama T, Nagatsuma T (2013) Comparison of ionosphere characteristic parameters obtained by ionosonde with IRI-2007 model over Southeast Asia. Adv Space Res 52(10):1748-1755

Yang J, Zhang D, Frangi AF, Yang J-Y (2004) Two-dimensional PCA: a new approach to appearance-based face representation and recognition. IEEE Trans Pattern Anal Mach Intell 26(1):131-137

Yizengaw E, Moldwin MB, Galvan D, lijima BA, Komjathy A, Mannucci AJ (2008) Global plasmaspheric TEC and its relative contribution to GPS TEC. J Atmos Solar Terr Phys 70(11-12):1541-1548

\section{Submit your manuscript to a SpringerOpen ${ }^{\circ}$ journal and benefit from:}

- Convenient online submission

- Rigorous peer review

- Open access: articles freely available online

- High visibility within the field

Retaining the copyright to your article

Submit your next manuscript at springeropen.com 